\title{
Supporting Informal Learning at the Workplace
}

\author{
doi:10.3991/ijac.v2i3.1004 \\ Pieter De Vries, Heide Lukosch \\ Delft University of Technology, Delft, Netherlands
}

\begin{abstract}
In times of rapid technological and socioeconomic changes, knowledge sharing and learning have become critical assets for most organizations and companies. New ways of learning and training are needed to cope with the rising demand of information. The Microtraining method developed on basis of recent learning theories and concepts is an answer to the need of flexibility of learning settings related to space and time, the availability of experts and the applicability of what is learned and trained at the workplace. This concept of informal learning comprises short learning sessions with work related topics. These learning occasions facilitate informal learning at the workplace on individual as well as on organizational level, as can be seen from two case studies.
\end{abstract}

Index Terms-Informal Learning, Microtraining, Learning at the Workplace.

\section{INTRODUCTION}

In organizations, learning happens all the time in a multitude of learning situations which can take place in a classroom, but obviously occurs most of the time in informal settings like a discussion amongst colleagues or a search session at the internet. The nature of learning at the workplace is different from classroom learning. The workplace environment can provide rich opportunities for informal learning like creating new modes of action, new practices, new processes and products both individually or in groups [22]. In addition, research has shown that there is a gap between the knowledge needed at the workplace and the knowledge and skills deriving from formal learning [22]. But still, it is about $80 \%$ of the training budget that goes to formal learning which means that companies overinvest in formal training programs, while missing out on the opportunity to foster the more natural and informal learning processes $[2 ; 8]$.

It is crucial to develop flexible mechanisms that support informal learning while avoiding the drawbacks that coincide with informality like difficulties to structure learning occasions, to measure the outcome of trainings or to transfer the lessons learned into reusable knowledge. The Microtraining method (MT) is such a concept to support ongoing informal learning practices in organizations. Microtraining helps to structure individual self learning actions and materials, e-learning and other learning activities, while focusing on the applicability of what is learned and needed in the workplace.

Microtraining is especially suitable for those whose basic knowledge needs to be refreshed or improved and who need information that can be used immediately in their daily practice, like information about new tools or technologies. The Microtraining method is developed on the basis of learning theories and concepts such as social constructivism and connectivism to support informal and both individual and collective learning in organizations. Experiences with the Microtraining method in practice show that the short, structured procedure of a Microtrainingsession or a serial of learning sessions connects people with each other and offers a way to deal with the challenges of today's learning demands of workplace related learning. In this paper, we will show the theoretical backgrounds and structure of the Microtraining method as well as experiences with this approach in practice.

\section{FORMAL AND INFORMAL LEARNING AT THE WORKPLACE}

Nowadays formal learning, mostly taking place in training settings far away the workplace, is the way of learning most companies spend a lot of money for. A company has a great influence on planning, structuring and controlling the learning activities of their employees with that way of learning [23]. But it shows that formal learning alone is not flexible enough to react on fast changes taking place in today's companies' surroundings. Learning at the workplace needs both formal and informal learning approaches. Learning in this sense is seen as an active and productive process of creating new knowledge, added to the learning concepts of knowledge acquisition and knowledge participation in communities [22]. The term of informal learning describes learning taking place outside of training institutions, but which surely can be planned and structured [23, 22].

Companies choosing for formal learning alone are not able to benefit from the advantages of informal learning settings like its flexibility in terms of time and space. Companies seem to overinvest in formal learning settings because learning in a formal structured way is very well known. The overinvestment in formal learning can also lead to a consolidation of formal learning structures in organizations like training departments delivering readymade courses and learning materials. Formal learning is a successful approach for those who have less knowledge and skills [22], but can be counter-productive for more experienced employees [9]. For those, informal blended learning approaches seem to work very well $[9,10]$.

That means that ways of learning are needed at the workplace which can respond to the demands of a rapid development of needed application-oriented knowledge. Most ideas of e-learning-settings are based on the challenge to design more flexible ways of learning. In many cases, this leads to carry over the old-fashioned classroom-courses to flashy-looking e-learning scenarios, where still an isolated learner widens his knowledge separated from his workplace [7].

Criticism on approaches like this is also related to the discussion about formal and informal learning. According to Digenti [8] and Cross [2] formal learning does not work anymore, because this kind of learning only responds to 
10 or 20 per cent of the knowledge people need at their workplaces. The overall 80 per cent are covered by informal learning activities on the workplace. Informal learning is seen as a more important critical success factor than formal learning settings [2].

Informal learning at the workplace occurs within daily interactions and shared relationships in companies, independently from professionally structured or pedagogically planned programs. Informal learning is a cooperative action while formal learning often takes place as an individually (or lonely) activity. Many activities at work require collaboration with other people [22], so employees are used to this way of working and learning. Because informal learning is characterized by contextual reasoning and produces implicit and tacit knowledge as well as situation-specific competences [22], informal learning enables people to cope with situations and problems occurring in their daily work practice, while building up communities of practice.

Informal learning occurs to be a way of learning difficult to deal with and to profit from for many companies. Informal learning is hard to be predictable. Additionally, even if informal learning shows a very generic way of learning, it is hardly been seen as learning itself. That is because it mainly is arranged individually and responsibility lies in the learner's hands. The responsibility for the learning outcome often lies in the hands of the learner, not in the hands of a trainer or coach $[2 ; 5]$. It is the way of learning where the learner is the one to define the planning, managing and controlling of where and when to learn [23]. Sometimes, learning in this sense seems to be a side effect of work.

In summary, this shows that we cannot see the difference between formal and informal learning at the workplace as a strict segregation between two sites or learning activities. We see learning as a spectrum of possibilities, which ranges from formal learning oriented on classroom structures to informal learning seen as a self directed and social activity (see figure 1).

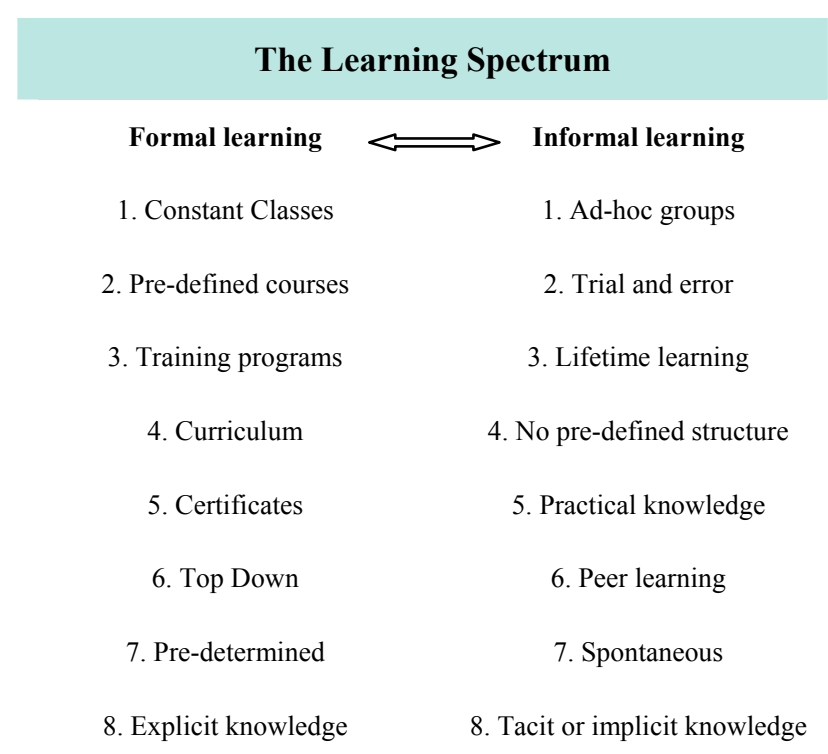

Figure 1. The Learning Spectrum (based on [4])
After showing some crucial aspects of formal and informal learning at the workplace, we want to pay our attention to an approach to promote informal learning at the workplace, to the concept of Microtraining.

\section{The Microtraining Method}

We see learning as an active process of knowledge creation that takes place in social interaction, not as a lonely activity. People use social networks in their work and for informal learning processes. For planning and initiating those learning processes and evaluating the progress, well-developed systems are needed [22]. The Microtraining method is an approach to structure these activities with the aim to enable people and organizations to benefit from informal learning scenarios and to be able to create and maintain new knowledge. The focus of these activities lies in the applicability of what is learned and needed in the workplace [4].

A Microtraining arrangement comprises a time span of 15-20 minutes for each learning occasion, which can activate and maintain learning processes for a longer period if they are bundled up in series, being face-to-face, online or in an e-learning situation. Microtraining is especially suitable for those whose basic knowledge needs to be refreshed or improved and who need information for immediate use in their daily practice. The Microtraining concept is based on several theoretical considerations as shown below.

The theory of social constructivism $[23 ; 24]$ gives important input to the idea of Microtraining. Training models based on the principles of the social constructivism seem to work well for informal, practical and spontaneous learning [4]. The main principles are that each person is unique regarding to knowledge and experience. People primarily learn by actively trying and learning always is related to a particular social context. The learner plays a central role in the development of learning activities with the aim to make learning more efficient. As a consequence, motivation becomes an important stimulating factor; experiences from the past always play a role and each person has his or her approach to learning, very much related to knowledge and experience acquired in the past. The Microtraining method is applicable to individual questions and problems and offers individual ways of information gathering and learning. The overall findings of the constructivism are very helpful for the development of learning programs such as single Microtraining sessions, but are less useful to tell about new ways of communication or collaboration such as so called social software.

To comprehend such ways of learning, the concept of connectivism is also very useful $[20 ; 21]$. It helps to understand how the inclusion of informal learning and the inclusion of technology as part of a learning strategy can work. The concept itself derives from recent developments in society related to the increasing amount of information, and the knowledge which is needed in everyday life. Siemens observed that the surrounding of knowledge changes regarding to the context knowledge appears in and regarding the flow and characteristics of the knowledge itself. By the quick emerge of new information media, the knowledge landscape is changing. In this new situation learning is more and more the ability to connect to different 'nodes' of knowledge, which are spread over a network of data, information and people and is called 
'connected knowledge' [21]. This includes that learning does not take place inside a learner, but is a social process of exchange and externalization. The concept of Microtraining facilitates this process by connecting people with each other and with different artifacts of knowledge they need at the workplace.

Assuming that people are unique learners, they also have different experience levels. According to Jonassen $[9 ; 10]$ this should be taken into account to clarify the different needs related to knowledge and experience. In general, three levels are distinguished: early development, competent and experienced, expert. A newcomer needs well structured, formal learning settings to support him or her with basic knowledge and skills in an appropriate way. More experienced employees with advanced knowledge and skills are better served with a largely informal learning situation that fits the rather ad hoc learning needs, so common for workplace related learning. For people with expert knowledge and experiences, formal and structured learning can even become counter-productive, because it does not fit the very personal learning needs [9]. These levels of experience serve as an indicator of the areas where the Microtraining method can be applied to. It is rather suitable for those who have basic knowledge and who need to refresh or to connect new knowledge to existing skills and competences than for newcomers.

Taking into account the learning theories and concepts shown above, Microtraining is a way to deal with individuals learning needs and experiences within an organizational setting and the idea that learning is an active, shared process. Microtraining supports the development of short, customized learning sessions for different groups of employees with the focus on workplace related learning needs.

The Microtraining approach is based on the idea that several short learning occasions, bundled up to one Microtraining arrangement, foster this active process of knowledge gathering and sharing. It refers to the different organizational levels, taking into account questions of work processes, learning content, technology and business development. Learning should be part of the work process and not an interruption. As an answer to this, the Microtraining method facilitates learning directly at the workplace without the need to change place or to attend courses at a specific time. The content of learning is linked to the needs at the workplace and supports the transfer from knowledge to daily work processes. It can be delivered by technology which supports knowledge sharing and retaining. With the use of collaborative technology, Microtraining does not support the progress of the individual alone but also of the whole organization.

Each Microtraining session is structured the same way. It starts actively, followed by a demonstration or exercise, feedback or short discussion, and ends with directions for further development and a brief preview of the next session $[15 ; 5]$ (see figure 2). It is important that the active start does not mean any directive from the management but an activity suggested by the employee him- or herself. This can be a question from a client as well as a technological problem or the upcoming of a new product.

The main goal of the Microtraining activities is to establish an effective way of learning by offering short learning occasions with a minimum of interruptions of the normal workflow. The sessions can be organized quickly
Each Microtraining session is structured in the same way

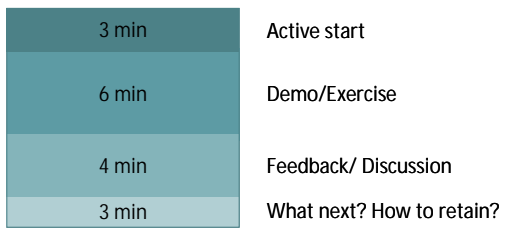

Each series of sessions is structured in the same way

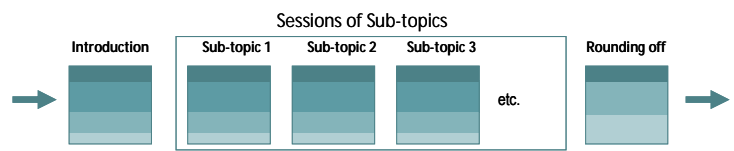

Figure 2. The Microtraining Workflow [15]

by any internal or external acteur, referring to current needs and demands. To create sustainable learning outcomes, the design of the learning occasions has to take into account the knowledge and experience of the individual learner or learning group.

To facilitate the active self-directed learning activities of the employees, some organizational requirements have to be fulfilled. It is important that the Microtraining method cannot be supported by hierarchical control and standardized learning situations, but by decentralized and autonomous working units which integrate individual learning in the daily workflow. Because active, selfdirected informal learning is new to many companies and employees, it is important that a coach or trainer accompanies the start of implementing the Microtraining method in an organization. It is also crucial to offer an adequate (technical) infrastructure to foster cooperation in daily work.

The characteristics of the Microtraining method illustrate that it is an opportunity for today's learners and trainers to foster informal learning at the workplace. Two examples of Microtraining in practice show how it can be applied in practice.

\section{PRACTICAL EXPERIENCES}

Different workplaces offer different opportunities for learning. Learning on the workplace is related to aspects like the organization of work processes, the possibilities for interaction between employees, the technological infrastructure, and the culture of participation. Recent experiences with the Microtraining method show its applicability to facilitate informal learning at the workplace $[15 ; 19 ; 6]$. With the help of this method, people can be brought together and solve problems in cooperation. Individuals connect with each other, collaborate and produce sustainable solutions which can be used companywide. With implementing learning activities in the daily workflow, a quick transfer from knowledge to work practice is enabled. Learning time can be used efficiently and with a focus on individual learning needs.

\section{A. The transport company portal example}

Our first example is the application of the Microtraining method in a Dutch transport company [6]. The transport world in general shows a mastery of logistics with coordinating the transport of goods, transport chains, freight handling and planning arrangements. Rapid changes in the 
regulations and the organization of the transport sector make innovation an absolute necessity.

The main activity of the Dutch transport company Van der Wal is road transport, so most of the employees spend their days behind the steering wheel. This organization has chosen the Microtraining method as core learning approach and implemented it in its common learning strategy. The aim was to reach a percentage of informal learning settings to be $90 \%$ of all learning activities. By changing the learning strategy from formal to informal learning, an overall performance improvement should be reached.

The main target group of the learning activities are the company's lorry drivers. They are no experienced learners but have an increasing demand on information and learning. Key elements of the strategy within this transport company are information exchange and improving of learning and performance. Microtraining has been realized within the on-site organizational learning activities, but also as mobile learning on the go.

As a first step, an action plan with several actions was developed by the company and an external consultant. A reference measurement was accomplished to carry out the state of the art of learning activities and performance aspects of the company. By comparing target and actual learning processes, a new learning policy was developed. The results were integrated in the strategic business plans of the transport company. This emphasizes on the importance of learning for the organizational performance and could be used as a framework to define basic and annual work profiles with individual learning needs.

Existing information resources in the company were complemented through interviews and a survey focusing on the communications needs of employees and management. It showed that especially the lorry drivers are in need of professional information. At this time their main informants were colleagues $(85 \%)$. The monthly paper newsletter was considered an important information source. Online information had not yet arrived as an alternative, but it was decided to extend this tool to an electronic newsletter and pilot this product over e period of time. The aim of this was to find out which functionalities were needed and what was needed to establish a $24 / 7$ news service. Given the importance of interaction and cooperation the focus for the technology selection was on social software tools. As a useful alternative to other systems, the Drupal content management was selected. This open source software fits to the company's demands of skills, flexibility and budget. The core idea behind using this system was to enable the company to develop learning material and courses by themselves.

The information platform based on the Drupal system was developed in a second step and was based on the Microtraining approach with its short learning sessions. It is structured through different 'information areas'. The platform contains the news forum as well as learning material and courses. Its content is divided into special issues related to the different working areas of the company. The system offers the possibilities to easily add content such as video clips send from the lorry driver's mobile phones to the system.

To become familiar with the Microtraining method itself, the managers of the company were trained in the use of it for learning related purposes. In a series of workshops they dealt with the need for well trained and in- formed staff, the Microtraining methodology, Microtraining development and online course production based on the Microtraining method.

For the employees of Van der Wal's transport company opportunities to attend place and time fixed learning activities is very limited due to their mobile workplaces. On the other hand, e-learning makes learning less place and time dependent. To implement this way of flexible learning, an online course about a new technical device, the Digital Tachograph, was developed on the basis of the Microtraining method. The layout of the course was based on short sessions with activating learning activities situated in a workplace context to inspire the learner. In the long term, the purpose is that the company will become largely self supporting in the development and maintenance of these kinds of learning events.

Key experiences in this company show that in the first line the electronic newsletter is highly appreciated by the lorry drivers. Employees and managers contribute to the news flow by sending in messages, links, reports, pictures, mobile phone video clips, etc. All information is being tagged to allow easy access to topic related information. Also the online learning course in the Digital Tachograph is used frequently. It was developed in close collaboration with the end users. A first test showed that the users liked the electronic opportunity, had virtually no difficulties with the navigation and considered the information given as informative and useful. The experiences with the Microtraining method, used as an approach to build up a company-wide information and learning system, was successfully in terms of learning purposes. Next steps of evaluation have to show if also the work performance could be improved with applying the Microtraining method for supporting informal learning at the workplace.

\section{B. The do-it-yourself learning example}

Our second example of Microtraining in practice shows a semantic-based knowledge platform in the Do-ityourself (DIY) branch. This platform is the outcome of the project "RELOAD" funded by the European Union. Core aim of this project is to support the employees of this sector with learning and information.

In general, the Do-it-yourself (DIY) branch is confronted with an increasing amount of manufacturer's information which must be transferred quickly to the daily work practice. On the other hand, the demographical structure of the branch shows that employees are older and have less learning experience. For these kinds of employees the rising amount of information is a difficult challenge [3].

To cope with the characteristics of the older and less experienced employees, a didactical concept has been developed on basis of the Microtraining approach. The didactical concept takes into account the challenges of the branch related to information needs as well as pedagogical answers how to deal with knowledge and learning in the specific work situation of do-it-yourself-markets. The Microtraining method is a crucial element of the didactical concepts. It is used to describe the structure of a knowledge platform implemented at the do-it-yourself-markets. The content of the platform is divided into several short information and learning units. The platform is also based on the idea of a semantic web to facilitate self-directed and media supported learning. For that purpose, a knowl- 
edge platform was designed and implemented in two companies of the German Do-it-yourself branch. The overall idea of these activities was to support informal learning processes at the workplace to support the employees of the do-it-yourself-markets with information whenever and wherever it is needed.

After the platform was designed and implemented, manufacturers as well as the companies itself were able to develop own Microtraining activities for the platform and deliver them to their employees. The employees on the other hand had easy access to a large amount of updated information. In practice, the question of a customer could be the active start for a Microtraining session. The platform offers the employee several ways of access to the given information, like a search engine, a library, a toolfinder and a so-called application-house, where information can be searched by different topics in an interactive 3D-illustration of a construction site. All information stored on the platform is also based on a semantic structure, which offers the possibility to connect the learning modules with each other and allows a self-directed, nonlinear way of learning.

The knowledge platform was used in a pilot phase in two German Do-it-yourself companies. After the pilot phase, interviews were held with selected employees. The interviews showed that that a well-structured and accompanied initial phase for the new way of learning was of high importance, especially for those how had less learning experience. The way of self-directed learning with the help of a new tool like the RELOAD-platform seems to be a difficult challenge for this group of employees. It was helpful that there was (initial) help of a trainer or coach to get used to this new way of learning.

As a second result we see that organizational requirements are also of high importance. For a real learning on the workplace it is necessary to provide each learner with the needed (technical) infrastructure. For some employees, access to a computer was very difficult and they had to leave his or her workplace which seemed to be almost impossible. Because of this, the platform was not used after one or two try-outs any more. Instead of this, traditional ways of information gathering like asking a colleague or calling the manufacturer remained instead of using the new learning opportunities.

In some cases it was not clear whether the employees could use some of their working time for learning purposes or not and some did not had time at all to use the platform. This shows that implementing the new way of learning into the companies' business plans is a necessity for the success of new learning strategies. The management has to support new ideas which should be clear to all employees.

The two cases shown here illustrate that organizational requirements, facilitating the new learning concept by the management and accompanying the initial phase of implementing the Microtraining method are crucial for its success. Because of this, the Microtraining method is not meant to be an approach for designing learning materials alone, but to analyze learning processes in organizations and support change management of learning strategies in a whole.

\section{CONCLUSIONS}

In summary, companies nowadays are hardly aware of the advantages of informal learning processes taking place at the workplace. The value of informal learning is evident, and the Microtraining method is an approach to deal with organizational requirements as well as with individual learning needs. Microtraining connects different aspects of learning and facilitates individual and connective learning with the focus on important topics of every day working practice.

The application of the Microtraining method in the case studies shows that Microtraining is useful for continuous learning and knowledge building processes taking place at the workplace. The case studies in this article also show that the Microtraining method is applicable at different working environments. With Microtraining, it is possible to activate the collaboration of groups and to enhance a company's communication. The examples illustrate that for some companies the application of this learning method is quite difficult. Management's commitment is crucial for the success of implementation.

The Microtraining method is based on learning theories and concepts to facilitate collaborative informal learning processes in an organization, addressing both urgent and long-term learning needs. Because the Microtraining units are short and the structure is consistent as well as easy to be understood, this way of learning offers organizations an individual and flexible way of learning. Microtraining facilitates processes of motivating and supporting the employees' responsibility for their own learning success and the transfer of knowledge to others and to their daily work tasks.

Further steps to be taken now are to implement the Microtraining method at further organizations to analyze further work situations to which the Microtraining method can be applied to and to improve the method itself.

\section{REFERENCES}

[1] Colley, H./Hodkinson, P. et al.: Informality and formality in learning: a report for the Learning and Skills Centre. Leeds: Life Long Learning Institute: University of Leeds, 2003.

[2] Cross, J.: Informal Learning: Rediscovering the Natural Pathways that Inspire Innovation and Performance. Pfeiffer, San Francisco, 2007.

[3] Dawidowicz, S., Süßmuth, B.: Demographische Trends 2007. Analyse und Handlungsempfehlungen zum demographischen Wandel in deutschen Unternehmen. On: http://www.de.capgemini.com/m/tl/Demographische Trends 200 7.pdf

[4] De Vries, P. \& Brall, S.: Microtraining as a Support Mechanism for Informal Learning. In: Elearningpapers of Elearningeuropa, on: http://www.elearningpapers.eu/, 2008.

[5] De Vries, P. \& Leege. T.: Final Report WP 1: Baumärkte und Lernen: eine Bedarfsanalyse. Reload project. DE/07/LLPLdV/TOI/147058. Leonardo Project European Union, 2008.

[6] De Vries, P., Pijper, G., Van der Wal, H.: Informal learning and the Concept of Microtraining. In: Conference proceedings of the Online Educa Berlin, 2008.

[7] De Vries, P., Veen, W., Veeningen, C.: Networked Learning in a Mulitnational Company: An innovative Approach to Collaborative Learning. Conference Proceedings EDMedia, Vienna, 2008.

[8] Digenti: Make space for Informal Learning. ASTD Learning Circuits. On: http://www.learningcircuits.org/2000/aug2000/digen ti.html, 2008.

[9] Jonassen, D., Mayes, T., \& McAleese, R.: A manifesto for a constructivist approach to uses of technology in higher education. In T.M. Duffy, J. Lowyck, \& D.H. Jonassen (Eds.), Designing envi- 
ronments for constructive learning. Springer-Verlag, Heidelberg, 1993, pp. 231-247.

[10] Jonassen, D. H.: "Instructional Design Models for Well-Structured and Ill-Structured Problem-Solving Learning Outcomes". In: Educational Technology Research and Development 45 (1): 1997, pp. 65-94. (doi:10.1007/BF02299613)

[11] Levy A. and U. Merry, Organizational Transformation; Approaches, strategies, theories, Praeger Publishers, New York, 1986.

[12] Lukosch, H., Overschie, M.F.G., Vries, Pieter de: Microtraining as an effective way towards sustainability. Proceedings of EDULEARN 09, 2009.

[13] Lukosch, H., Vries, Pieter de: Mechanisms to support Informal Learning at the Workplace. Proceedings of ICEWL09, New York, 2009.

[14] O'Sullivan, D.: Framework for Managing Development in the Networked Organizations. Journal of Computers in Industry 47 (1): 77-88. Elsevier Science Publishers B.V, 2002.

[15] Overschie, M.: Microteaching Manual: Effective transfer of knowledge for Sustainable Technological Innovation. On http://www.microteaching.org, August 2007.

[16] Overschie, M.G.F., M. Pujadas, A. Espuna, P. de Vries, Microteaching to support incremental innovations for sustainability, Results of the Microteaching project in the Netherlands and Spain, The Greening of Industry Network (GIN), June 26-28, 2008, Leeuwarden, The Netherlands, 2008.

[17] Overschie M.G.F., P. de Vries, A. Espuna, A. Meluni, S. Brall, K. Weingarts-Göttgens, Effective learning to support incremental innovations towards sustainability, EESD 2008, Graz, Austria, 2224 September 2008 http://eesd08.tugraz.at/.

[18] Rosenberg, M. J.: Beyond E-Learning. Approaches and Technologies to Enhance Organizational Knowledge, Learning, and Performance. Pfeiffer, 2006.
[19] RWTH Aachen: Final Report Microteaching - Modular Teaching and Learning Solutions for a needs based education. Aachen, RWTH, 2007.

[20] Siemens, G.: Connectivism: A Learning Theory for the Digital Age. In: International Journal of Instructional Technology and Distance Learning, Vol. 2, No. 1, 2005.

[21] Siemens, G.: Knowing Knowledge. Lulu Publishers (www.lulu.com), 2006.

[22] Tynjälä, Päivi: Perspectives into learning at the workplace. Educational Research Review 3 (2008), pp. 130-154. (doi:10.1016/j.edurev.2007.12.001)

[23] Vygotsky, L.S. Mind and society: The development of higher mental processes. Harvard University Press, Cambridge, MA, 1978.

[24] Weistra, H.: Leerenergie en de voorwaarden voor (in) formeel leren (Energy for learning and the prerequisites for (In) formal Learning). In: Opleiding en Ontwikkeling, Oct. 2005, pp 17-21.

[25] Wertsch, J. V.: Vygotski and the formation of the mind. Cambridge, 1997.

\section{AUTHORS}

Pieter de Vries is Assistant Professor at Delft University of Technology, P. O. Box 5015, 2600 GA Delft, The Netherlands and owns his own E-Learning consultancy. (e-mail: Pieter.devries@tudelft.nl).

Heide Lukosch is Assistant Professor at Delft University of Technology, P. O. Box 5015, 2600 GA Delft, The Netherlands. (e-mail: h.k.lukosch@tudelft.nl).

This article was modified from a presentation at the ICELW 2009 conference in New York, NY, USA, June 2009. Submitted, July 5, 2009. Published as resubmitted by the author(s) on July 5, 2009. 